\title{
Sex Differences in Lower Urinary Tract Symptoms in Older Korean Adults Living in Rural Areas: Prevalence, Quality of Life, and Associated Factors
}

\author{
Jeongok Park ${ }^{1}$, Eun Sook Kim¹, Young Joo Lee ${ }^{2}$, Hyo Serk Lee ${ }^{3}$, Ju Tae Seo ${ }^{3}$ \\ ${ }^{1}$ Mo-Im Kim Nursing Research Institute, College of Nursing, Yonsei University, Seoul, Korea \\ ${ }^{2}$ College of Nursing, Daegu Catholic University, Daegu, Korea \\ ${ }^{3}$ Department of Urology, Cheil General Hospital \& Women's Healthcare Center, Dankook University College of Medicine, Seoul, Korea
}

Purpose: Urinary incontinence (UI) is associated with nursing home admission, functional decline, and risk of death among community-dwelling older adults. Little information, however, is available on sex differences in lower urinary tract symptoms (LUTS) in older Korean adults exclusively living in rural areas. This study examined sex-related differences in LUTS, factors associated with UI in older adults living in rural areas, and health-related quality of life (HRQoL) in incontinent older adults. Methods: This was a cross-sectional study in which face-to-face interviews were conducted at 15 rural community-health centres. A total of 323 older adults aged $\geq 65$ years from rural areas of Korea participated. LUTS prevalence was evaluated and HRQoL was measured using the King's Health Questionnaire. The chi-square test and t-test were used to examine sex differences in characteristics, LUTS, and HRQoL. Multivariable logistic regression was used to identify risk factors associated with UI. Results: Nocturia was the most prevalent symptom, affecting $87 \%$ of men and $86 \%$ of women. Women (53\%) had significantly more UI of any kind than did men (35\%) $(\mathrm{P}=0.007)$. Urgency UI was the most frequent type of UI in men, whereas stress UI was the most frequent in women. Regarding HRQoL, men had significantly higher scores in the domains of sleep/energy disturbances $(\mathrm{P}=0.032)$ than did women, and women reported greater effects from the severity of incontinence $(\mathrm{P}=0.001)$ than did men. Arthritis was the only factor associated with UI in men (odds ratio [OR], 6.88; 95\% confidence interval [CI], 1.4632.36). However, women with diabetes mellitus were less likely to have UI than those without (OR, $0.43 ; 95 \%$ CI, $0.23-0.82$ ). Conclusions: LUTS were found to be highly prevalent in community-dwelling older Korean adults in rural areas. Interventions to improve sleep and to reduce UI severity are needed for incontinent men and women, respectively.

Keywords: Aged; Lower urinary tract symptoms; Quality of life; Urinary incontinence; Nocturia

- Grant/Fund Support: This work was supported by a National Research Foundation of Korea (NRF) grant funded by the Korean government (MSIP) (No. 2015R1C1A1A01054434).

- Research Ethics: This study was approved by the Institutional Review Board of Yonsei University (2016-0004-1), and written informed consent was obtained from all participants.

- Conflict of Interest: No potential conflict of interest relevant to this article was reported.

Corresponding author: Jeongok Park (iD https://orcid.org/0000-0003-4978-817X Mo-Im Kim Nursing Research Institute, College of Nursing, Yonsei University, 50-1 Yonsei-ro, Seodaemun-gu, Seoul 03722, Korea

E-mail: jopark02@gmail.com / Tel: +82-2-2228-3390 / Fax: +82-2-392-5440

Submitted: April 27, 2018 / Accepted after revision: June 29, 2018
This is an Open Access article distributed under the terms of the Creative Commons Attribution Non-Commercial License (http://creativecommons.org/licenses/by-nc/4.0/) which permits unrestricted non-commercial use, distri-
bution, and reproduction in any medium, provided the original work is properly cited. 


\section{INTRODUCTION}

According to the Korean Statistical Information Service, the life expectancy of Koreans at birth in 2014 was 82.4 years, and adults aged $\geq 65$ years will account for $20 \%$ of the population by 2025 [1]. Additionally, the proportion of older adults is greater in rural areas than in Korea as a whole. As the older population increases, health care providers' interest in lower urinary tract symptoms (LUTS) is also growing because LUTS increase with age $[2,3]$. LUTS can be categorised into storage, voiding, and postmicturition symptoms [4]. Storage symptoms include frequency, nocturia, urgency, and urinary incontinence (UI), and voiding symptoms include slow stream, splitting, intermittent stream, hesitancy, straining, and terminal dribble. A feeling of incomplete emptying and postmicturition dribble are postmicturition symptoms. According to population-based studies [2,3], older men have more voiding and postmicturition symptoms than do older women. Moreover, men aged $\geq 70$ years have shown a higher prevalence of storage symptoms than women aged $\geq 70$ years [3].

Among LUTS, UI is associated with nursing home admission, functional decline, and risk of death among communitydwelling older adults [5]. UI also negatively affects individuals' health-related quality of life (HRQoL) [6]. Specifically, urgency UI decreases HRQOL more than other types of UI in older adults [6]. To date, however, little information is available on sex differences in LUTS, factors associated with UI, and HRQoL in older Korean adults exclusively living in rural areas.

The purposes of this study were to examine sex-related differences in the prevalence of LUTS and factors associated with UI in community-dwelling older adults living in rural areas and to explore HRQoL in incontinent older adults.

\section{MATERIALS AND METHODS}

\section{Study Design and Sample}

A cross-sectional design was used for this study of adults aged $\geq 65$ years in rural areas of Korea. For data collection, face-toface interviews were conducted at 15 rural community-health centres by research assistants who were nurses and received standardised training for data collection. The exclusion criteria were (1) the self-reported presence of symptoms of urinary tract infection, (2) receiving any treatment for LUTS, or (3) decreased cognitive function as assessed using the Korean version of the Mini-Mental State Examination-Dementia Screening [7].
A total of 380 adults participated, of whom 323 (men, 75; women, 248) met the inclusion criteria for this study. This study was approved by the Institutional Review Board of Yonsei University (2016-0004-1).

\section{Measures}

To collect information on LUTS, interviews were conducted using the questionnaire that was utilized in the study of Lee et al. [3], which was originally developed by Irwin et al. [2]. Participants were asked about storage symptoms (nocturia, frequency, urgency, UI), voiding symptoms (terminal dribble, slow stream, straining, intermittency), and postmicturition symptoms (incomplete emptying, postmicturition dribble).

Participants were considered to have UI if they answered "several times a week" or "every day" to the question "How often do you leak urine?" Participants with UI were then asked whether they had stress UI ("Do you experience urine leakage when you sneeze, cough, or exercise?") and/or urgency UI (“Do you experience urine leakage when you have a sudden urge to urinate?"). Participants with both stress and urgency UI were considered as having mixed UI. Participants were considered to have overactive bladder (OAB) if they answered "yes" to the question "Do you experience sudden urges to urinate and have difficulty in holding urine?" and answered "several times a week" or "every day" to the question "How often do you have this experience?"

To measure HRQoL among participants with UI or OAB, defined as a feeling of urinary urgency with or without urgency UI, the Korean version of the King's Health Questionnaire was administered [8]. This questionnaire was originally developed by Keller and colleagues in 1997 and consists of 21 items and 8 domains (general health perception, impact on life, role limitations, physical limitations, social limitations, personal relationships, emotions, sleep/energy), with a separate scale for measuring the severity of urinary symptoms [9]. Each item is scored on a 4-point scale, and the range of each domain is from 0 to 100 , with a higher score indicating a greater impairment of HRQoL. The Cronbach alpha of this questionnaire in the current study was 0.858 .

Information on the participants' age; education; marital status; self-reported health status; self-reported comorbidities such as hypertension, stroke, arthritis, diabetes mellitus (DM), and benign prostatic hyperplasia (BPH); falls; and instrumental activities of daily living were collected. The participants' height and weight were measured by a research assistant. 
Table 1. Comparison of characteristics and lower urinary tract symptoms between men and women

\begin{tabular}{|c|c|c|c|c|c|}
\hline Variable & Total $(\mathrm{n}=323)$ & $\operatorname{Men}(\mathrm{n}=75)$ & Women $(\mathrm{n}=248)$ & $\operatorname{tor} \chi^{2}$ & P-value \\
\hline Age (yr) & $77.4 \pm 5.9(65-94)$ & $77.4 \pm 5.7(66-89)$ & $77.4 \pm 5.9(65-94)$ & & \\
\hline $65-79$ & $202(62.5)$ & $46(61.3)$ & $156(62.9)$ & 0.69 & 0.953 \\
\hline$\geq 80$ & $121(37.5)$ & $29(38.7)$ & $92(37.1)$ & 0.06 & 0.806 \\
\hline \multicolumn{6}{|l|}{ Educational level } \\
\hline No education & $183(56.7)$ & $13(17.3)$ & $170(68.5)$ & 69.27 & $<0.001$ \\
\hline Elementary school & $87(26.9)$ & $32(42.7)$ & $55(22.2)$ & & \\
\hline$\geq$ Middle school & $53(16.4)$ & $30(40.0)$ & $23(9.3)$ & & \\
\hline \multicolumn{6}{|l|}{ Body mass index $\left(\mathrm{kg} / \mathrm{m}^{2}\right)^{\mathrm{a})}$} \\
\hline Underweight $(<18.5)$ & $2(0.6)$ & $0(0.0)$ & $2(0.8)$ & 0.94 & 0.624 \\
\hline Normal (18.5-24.9) & $142(45.5)$ & $36(48.6)$ & $106(44.5)$ & & \\
\hline Overweight/obese $(\geq 25)$ & $168(53.9)$ & $38(51.4)$ & $130(54.7)$ & & \\
\hline \multicolumn{6}{|l|}{ Marital status ${ }^{\mathrm{a})}$} \\
\hline No spouse & $164(51.6)$ & $18(25.0)$ & $146(59.3)$ & 24.96 & $<0.001$ \\
\hline Living with spouse & $154(48.4)$ & $54(75.0)$ & $100(40.7)$ & & \\
\hline \multicolumn{6}{|l|}{ Self-reported health status ${ }^{\text {a) }}$} \\
\hline Good & $104(32.8)$ & $24(32.8)$ & $80(32.8)$ & 2.52 & 0.642 \\
\hline Fair & $79(24.9)$ & $22(30.2)$ & $57(23.4)$ & & \\
\hline Poor & $134(42.3)$ & $27(37.0)$ & $107(43.8)$ & & \\
\hline No. of vaginal deliveries & $4.4 \pm 1.7(0-9)$ & NA & $4.4 \pm 1.7(0-9)$ & NA & \\
\hline \multicolumn{6}{|l|}{ Self-reported health problems } \\
\hline Hypertension & $216(66.9)$ & $54(72.0)$ & $162(65.3)$ & 0.88 & 0.349 \\
\hline Stroke & $13(4.0)$ & $6(8.0)$ & $7(2.8)$ & 2.77 & 0.096 \\
\hline Arthritis & $92(28.5)$ & $14(18.7)$ & $78(31.5)$ & 4.01 & 0.045 \\
\hline $\mathrm{DM}$ & $83(25.7)$ & $22(29.3)$ & $61(24.6)$ & 0.45 & 0.500 \\
\hline $\mathrm{BPH}$ & $13(4.0)$ & $13(17.3)$ & NA & NA & \\
\hline Falls & $96(29.7)$ & $20(26.7)$ & $76(30.6)$ & 0.27 & 0.606 \\
\hline $\mathrm{IADL}^{\mathrm{a})}$ & $10.24 \pm 1.17(10-21)$ & $10.16 \pm 0.70(10-15)$ & $10.26 \pm 1.28(10-21)$ & 0.70 & 0.488 \\
\hline \multicolumn{6}{|c|}{ Lower urinary tract symptoms } \\
\hline \multicolumn{6}{|l|}{ Storage symptoms } \\
\hline \multicolumn{6}{|l|}{ Nocturia } \\
\hline$\geq 1$ & $278(86.1)$ & $65(86.7)$ & $213(85.9)$ & 0.03 & 0.864 \\
\hline$\geq 2$ & $196(60.7)$ & $50(66.7)$ & $146(58.9)$ & 1.49 & 0.222 \\
\hline Frequency & $165(51.1)$ & $40(53.3)$ & $125(50.4)$ & 0.10 & 0.754 \\
\hline Urgency & $94(29.1)$ & $23(30.7)$ & $71(28.6)$ & 0.04 & 0.845 \\
\hline \multicolumn{6}{|l|}{ Urinary incontinence } \\
\hline Urgency & $76(23.5)$ & $14(18.7)$ & $62(25.0)$ & 0.96 & 0.328 \\
\hline Stress & $106(32.8)$ & $4(5.3)$ & $102(41.1)$ & 31.86 & $<0.001$ \\
\hline Mixed & $47(14.6)$ & $3(4.0)$ & $44(17.7)$ & 7.68 & 0.006 \\
\hline Other & $23(7.1)$ & $11(14.7)$ & $12(4.8)$ & 7.23 & 0.007 \\
\hline Any & $158(48.9)$ & $26(34.7)$ & $132(53.2)$ & 7.21 & 0.007 \\
\hline \multicolumn{6}{|l|}{ Voiding symptoms } \\
\hline Terminal dribble & $95(29.4)$ & $42(56.0)$ & $53(21.4)$ & 31.61 & $<0.001$ \\
\hline Slow stream & $160(49.5)$ & $58(77.3)$ & $102(41.1)$ & 28.76 & $<0.001$ \\
\hline Straining & $64(19.8)$ & $29(38.7)$ & $35(14.1)$ & 20.33 & $<0.001$ \\
\hline Intermittency & $76(23.5)$ & $23(30.7)$ & $53(21.4)$ & 2.27 & 0.132 \\
\hline \multicolumn{6}{|l|}{ Postmicturition symptoms } \\
\hline Incomplete emptying & $70(21.7)$ & $27(36.0)$ & $43(17.3)$ & 10.74 & 0.001 \\
\hline Postmicturition dribble & $25(7.7)$ & $13(17.3)$ & $12(4.8)$ & 10.90 & 0.001 \\
\hline
\end{tabular}

Values are presented as mean \pm standard deviation (range) or number (\%).

$\mathrm{DM}$, diabetes mellitus; $\mathrm{BPH}$, benign prostatic hyperplasia; IADL, instrumental activities of daily living; NA, not applicable.

${ }^{a)}$ Excluding missing data. 


\section{Statistical Analysis}

Statistical analyses were performed using IBM SPSS Statistics ver. 23.0 (IBM Co., Armonk, NY, USA). Descriptive statistics were used to describe the participants' characteristics, LUTS, and HRQoL. We used the chi-square test and the t-test to examine differences in characteristics, LUTS, and HRQoL between men and women. Multivariable logistic regression was used to identify risk factors associated with UI.

\section{RESULTS}

The characteristics of the participants are described in Table 1. The average age of the participants was 77.4 years (standard deviation, 5.9), and $38 \%$ were $\geq 80$ years old. Approximately $57 \%$ had no education, and $17 \%$ of the men and $69 \%$ of the women were illiterate $(\mathrm{P}<0.001)$. Three-quarters of the men and $41 \%$ of the women reported having a spouse $(\mathrm{P}<0.001)$. Hyperten-

Table 2. Comparison of health-related quality of life between men and women

\begin{tabular}{lccccc}
\hline Variable & Total $(\mathrm{n}=160)$ & Men $(\mathrm{n}=27)$ & Women $(\mathrm{n}=133)$ & $\mathrm{t}$ & $\mathrm{P}$-value \\
\hline General health perception & $58.0 \pm 24.5(0-100.0)$ & $51.9 \pm 24.9(0-100.0)$ & $59.2 \pm 24.3(0-100.0)$ & 1.43 & 0.155 \\
Impact on life $(\mathrm{n}=159)$ & $28.7 \pm 35.7(0-100.0)$ & $33.3 \pm 41.3(0-100.0)$ & $27.8 \pm 34.5(0-100.0)$ & 0.74 & 0.467 \\
Role limitations & $16.5 \pm 27.7(0-100.0)$ & $19.1 \pm 26.4(0-100.0)$ & $15.9 \pm 28.0(0-100.0)$ & 0.55 & 0.584 \\
Physical limitations & $14.9 \pm 25.5(0-100.0)$ & $16.0 \pm 21.4(0-66.7)$ & $14.7 \pm 26.3(0-100.0)$ & 0.26 & 0.797 \\
Social limitations $(\mathrm{n}=158)$ & $4.6 \pm 13.3(0-66.7)$ & $4.5 \pm 8.9(0-33.3)$ & $4.6 \pm 14.1(0-66.7)$ & 0.03 & 0.973 \\
Personal relationships $\left.{ }^{\mathrm{a}}\right)(\mathrm{n}=58)$ & $0.4 \pm 2.6(0-16.7)$ & $\mathrm{NA}$ & $0.4 \pm 2.6(0-16.7)$ & $\mathrm{NA}$ & $\mathrm{NA}$ \\
Emotional problems & $10.5 \pm 22.6(0-100.0)$ & $6.6 \pm 13.5(0-44.4)$ & $11.3 \pm 24.0(0-100.0)$ & 1.41 & 0.164 \\
Sleep/energy disturbances $(\mathrm{n}=159)$ & $22.3 \pm 34.3(0-100.0)$ & $38.9 \pm 44.1(0-100.0)$ & $18.9 \pm 31.1(0-100.0)$ & 2.24 & 0.032 \\
Incontinence severity $(\mathrm{n}=156)$ & $24.8 \pm 19.1(0-100.0)$ & $13.1 \pm 14.6(0-60.0)$ & $27.1 \pm 19.1(0-100.0)$ & 3.47 & 0.001 \\
\hline
\end{tabular}

Values are presented as mean \pm standard deviation (range).

NA, not applicable.

a) Results of 'not applicable' were excluded.

Table 3. Factors associated with urinary incontinence in men and women

\begin{tabular}{|c|c|c|c|c|}
\hline \multirow{2}{*}{ Variable (reference) } & \multicolumn{2}{|c|}{$\operatorname{Men}(n=71)$} & \multicolumn{2}{|c|}{ Women $(\mathrm{n}=234)$} \\
\hline & OR $(95 \%$ CI $)$ & P-value & OR $(95 \%$ CI $)$ & P-value \\
\hline \multicolumn{5}{|l|}{ Age (yr) } \\
\hline$\geq 80(65-79)$ & $0.88(0.22-3.44)$ & 0.850 & $0.80(0.43-1.52)$ & 0.499 \\
\hline \multicolumn{5}{|l|}{ Educational level (uneducated) } \\
\hline Elementary school & $0.19(0.03-1.20)$ & 0.077 & $1.51(0.73-3.09)$ & 0.264 \\
\hline Middle school & $0.53(0.09-3.17)$ & 0.482 & $0.74(0.24-2.28)$ & 0.601 \\
\hline \multicolumn{5}{|l|}{ BMI (underweight/normal) } \\
\hline Overweight/obese & $3.23(0.90-11.64)$ & 0.073 & $1.68(0.97-2.93)$ & 0.067 \\
\hline Living with spouse (no spouse) & $0.68(0.19-2.41)$ & 0.547 & $1.14(0.63-2.05)$ & 0.674 \\
\hline No. of vaginal deliveries & NA & & $0.91(0.76-1.08)$ & 0.263 \\
\hline Hypertension (none) & $0.99(0.23-4.17)$ & 0.983 & $1.17(0.65-2.11)$ & 0.592 \\
\hline Arthritis (none) & $6.88(1.46-32.36)$ & 0.015 & $1.55(0.85-2.85)$ & 0.155 \\
\hline $\mathrm{DM}$ (none) & $0.64(0.17-2.38)$ & 0.506 & $0.43(0.23-0.82)$ & 0.010 \\
\hline $\mathrm{BPH}$ (none) & $3.77(0.72-19.66)$ & 0.115 & NA & \\
\hline Falls (none) & $2.27(0.57-9.02)$ & 0.244 & $1.19(0.66-2.16)$ & 0.558 \\
\hline IADL (scores) & $1.66(0.65-4.26)$ & 0.293 & $1.01(0.82-1.26)$ & 0.906 \\
\hline
\end{tabular}

OR, odds ratio; CI, confidence interval; BMI, body mass index; DM, diabetes mellitus; BPH, benign prostatic hyperplasia; IADL, instrumental activities of daily living; NA, not applicable. 
sion was the most prevalent problem in both men $(72 \%)$ and women (65\%). Arthritis was the second most prevalent health problem and was significantly more prevalent in women than in men $(\mathrm{P}=0.045)$.

Nocturia, defined as waking at night $\geq 1$ time to void, was the most prevalent LUTS and affected $87 \%$ of men and $86 \%$ of women (Table 1). When nocturia was defined as voiding $\geq 2$ times per night, the prevalence was $61 \%$. Women (53\%) were significantly more often affected by UI of any type than men $(35 \%)(\mathrm{P}=0.007)$. Urgency UI was the most frequent type of UI in men, and stress UI was the most frequent in women. Regarding voiding symptoms, men reported significantly more terminal dribble $(\mathrm{P}<0.001)$, slow stream $(\mathrm{P}<0.001)$ and straining $(\mathrm{P}<0.001)$ than did women. Half of all participants experienced slow stream, which was the most prevalent voiding symptom in both sexes. Approximately $22 \%$ and $8 \%$ of the participants reported postmicturition symptoms of incomplete emptying and postmicturition dribble, respectively. Incomplete emptying $(\mathrm{P}=0.001)$ and postmicturition dribble $(\mathrm{P}=0.001)$ were both significantly more prevalent in men than in women.

The participants who had UI or OAB (men, 27; women, 133) responded to the King's Health Questionnaire. All domain scores are presented in Table 2. Men had significantly higher scores for the domains of sleep/energy disturbances $(\mathrm{P}=0.032)$ than did women, and women reported greater effects from the severity of incontinence $(\mathrm{P}=0.001)$ than did men. The results of our multivariate logistic regression for risk factors associated with UI are shown in Table 3. Among the men, arthritis was the only factor associated with UI; having arthritis significantly increased the odds of UI among older men (odds ratio [OR], 6.88; 95\% confidence interval [CI], 1.46-32.36). In contrast, women with DM were less likely to have UI than were women without $\mathrm{DM}$ (OR, 0.43; 95\% CI, 0.23-0.82).

\section{DISCUSSION}

In this study, we confirmed that LUTS were highly prevalent in older Korean adults living in rural areas. In the literature, nocturia has been reported to be the most prevalent symptom in older adults, with a prevalence of approximately $71 \%$ when defined as voiding $\geq 1$ time per night [2]. In contrast, the prevalence of nocturia has been reported to range from $36 \%$ to $52 \%$ when defined as voiding $\geq 2$ times per night in adults aged $\geq 60$ years $[2,10]$. Similarly, we found that the prevalence of nocturia was $86 \%$ and $61 \%$ using the former and latter definitions, re- spectively, and nocturia was the most-reported symptom.

UI has been reported to be more prevalent in older women (42\%-52\%) than in older men aged $\geq 65$ years $[11,12]$, which is consistent with our findings (34.7\% in men and $53.2 \%$ in women). Among community-dwelling older adults, we found that arthritis significantly increased the odds of UI in men, but not women, unlike the results of previous studies [13]. We found that urgency UI was the most prevalent type of UI in men, which is consistent with the results of a previous study [14]. In the present study, arthritis was found to be significantly associated with UI in older men. A possible explanation for this finding is that men who have arthritis might take more time to reach the toilet than men without arthritis, possibly experiencing urine leakage on the way. Another interesting finding in the current study was that DM decreased the odds of UI in women. Similarly, Jackson et al. [15] found that women with diabetes reported less stress and urgency UI than women without diabetes. They also found that women with diabetes had less slight or moderate UI measured by the Sandvik severity index, and more severe UI than nondiabetic women. Therefore, a possible explanation for our finding is that women with diabetes and severe UI might have been excluded from the current study due to having experience of treatment, such as medication and/or surgery for UI, which was one of the exclusion criteria for our study. It is well established in the literature that the severity of UI in women is significantly associated with seeking treatment [16]. Since the severity of UI was not examined in our study, more studies investigating the association between DM and UI in older women are needed. Although significant associations of advanced age [17], being overweight/obese [18], falls [19], and $\mathrm{BPH}$ [20] with UI have been reported in the literature, we did not find any such associations.

The participants with UI or OAB in the current study reported better HRQoL in most domains of the King's Health Questionnaire than in the study of Okamura et al. [21]. One possible explanation is that the participants in the study of Okamura et al. [21] were recruited at urology clinics; thus, their LUTS might have been more severe than those of our participants. Interestingly, however, the men in our study reported greater effects in the domain of sleep/energy disturbances than did those in the previous study. This finding might be associated with a higher prevalence of nocturia among the men in our study than was found among the men in the study of Okamura et al. Another interesting finding regarding the domain of sleep/energy disturbances was that the men had significantly 
lower HRQoL than the women, even though the prevalence of nocturia did not differ significantly between them. A study found an association between increased nocturnal voiding and subjective and objective sleep parameters [22], but that study also addressed obesity, sleep apnoea, fluid intake, and caffeine use, all of which could be associated with nocturnal voiding [23]. One possible explanation for our result is that older men might feel more exhausted or disturbed from waking to void at night than older women. Men had significantly more voiding and post-micturition symptoms such as slow stream, straining, and incomplete emptying than women; therefore, they might spend more time and effort to void than women.

Regarding sex differences in voiding symptoms, it has been found that voiding symptoms are more prevalent in men than in women. Cameron et al. [24] found that men had significantly more symptoms of weak stream ( $61 \%$ vs. $29 \%$ ), intermittency ( $53 \%$ vs. $25 \%$ ), hesitancy ( $48 \%$ vs. $24 \%$ ), and straining ( $28 \%$ vs. $19 \%)$ than women. The Korean EPIC study also found that voiding symptoms were more prevalent in men aged 65 years or older, and the age group of 70-96 years had the largest difference in the prevalence of voiding symptoms between men and women [3]. In a similar vein, the current study found that $30 \%$ to $77 \%$ of men reported voiding symptoms, and most symptoms (except intermittency) were significantly more prevalent in men than in women.

This study had several limitations. First, we used the convenience sampling method, defined as a selection of the most readily available persons as participants in a study [25], to recruit older adults. Thus, older adults with LUTS might have been overrepresented in our sample.

Second, reporting bias could have been present. Data collection was conducted by a research assistant through face-to-face interviews; thus, the participants' reported LUTS might have differed from their real symptoms. Face-to-face interviews for data collection seemed to be appropriate because approximately half of the participants were illiterate; however, it is possible that some of participants might not have accurately reported their LUTS because they might have considered LUTS to be an embarrassing condition [26]. Third, the information on the participants' health problems was self-reported and was not medically assessed, which might have led to inaccuracies in the data; therefore, our results must be carefully interpreted. For example, some of the men might have had undiagnosed early symptoms of BPH. Thus, the use of self-reported health conditions might have resulted in a weakened association between $\mathrm{BPH}$ and UI in men.

Finally, the current study included fewer men than women, which might have biased the results. Although the proportion of women to men aged 70-99 in the rural areas where we conducted the study was about 100 to 82 in 2016 [1], the sex ratio of women to men in the current study was about 3 to 1 . Therefore, careful interpretation of the results and more studies of sex differences in LUTS, using more representative sex ratios, are needed.

Despite these limitations, this study provides valuable information. This study focused on older adults living in rural areas; therefore, it provides useful information on the possible effects of characteristics of rural areas on LUTS. The rural area where we conducted this study is a province where the proportion of older adults is much greater than the average proportion in Korea as a whole ( $22 \%$ vs. $13 \%$, respectively). As older adults living in rural areas have relatively limited access to health care specialists and because their characteristics, such as educational level and living environment, are different from those of older adults living in cities or metropolitan areas (e.g., living in a single house vs. an apartment), information about their self-reported LUTS can provide baseline data for designing and providing person-centred interventions. The current study highlights that nocturia was the most prevalent LUTS in both sexes in rural areas. Thus, applying interventions to reduce nocturia would be important. Both behavioural interventions, such as restricting fluid intake and caffeinated drinks in the evening, and environmental interventions, such as providing a bedside commode, could be considered. Regarding arthritis, which was a factor associated with UI in men, health care providers should pay attention to UI in older men with arthritis.

In conclusion, LUTS were highly prevalent in older Korean adults living in rural areas. Interventions to improve sleep and to reduce UI severity are needed in men and women, respectively.

\section{ACKNOWLEDGEMENTS}

The authors would like to thank 15 community health nurse practitioners in Gapyeong-gun for their valuable help.

\section{AUTHOR CONTRIBUTION STATEMENT}

- Full access to all the data in the study and takes responsibility for the integrity of the data and the accuracy of the data analysis: JP 
- Study concept and design: JP, YJL, HSL, JTS

- Acquisition of data: JP, ESK

- Analysis and interpretation of data: JP, ESK

- Drafting of the manuscript: $J P, Y J L$

-Critical revision of the manuscript for important intellectual content: JP, YJL, HSL, JTS

- Statistical analysis: JP, ESK

- Obtained funding: $J P$

- Administrative, technical, or material support: JP, ESK

-Study supervision: $J P$

\section{REFERENCES}

1. Korean Statistical Information Service. Future population projection: 2015-2065 [Internet]. Daejeon (Korea): Statistics Korea; [cited 2018 Aug 2]. Available from: http://kostat.go.kr/portal/korea/kor_ nw/2/1/index.board?bmode=read\&aSeq=357935\&pageNo=\&row Num $=10 \& a m S e q=\& s$ Target $=\& s$ Txt $=$

2. Irwin DE, Milsom I, Hunskaar S, Reilly K, Kopp Z, Herschorn S, et al. Population-based survey of urinary incontinence, overactive bladder, and other lower urinary tract symptoms in five countries: results of the EPIC study. Eur Urol 2006;50:1306-14.

3. Lee YS, Lee KS, Jung JH, Han DH, Oh SJ, Seo JT, et al. Prevalence of overactive bladder, urinary incontinence, and lower urinary tract symptoms: results of Korean EPIC study. World J Urol 2011;29:18590.

4. Abrams P, Cardozo L, Fall M, Griffiths D, Rosier P, Ulmsten U, et al. The standardisation of terminology in lower urinary tract function: report from the standardisation sub-committee of the International Continence Society. Urology 2003;61:37-49.

5. Holroyd-Leduc JM, Mehta KM, Covinsky KE. Urinary incontinence and its association with death, nursing home admission, and functional decline. J Am Geriatr Soc 2004;52:712-8.

6. Coyne KS, Zhou Z, Thompson C, Versi E. The impact on health-related quality of life of stress, urge and mixed urinary incontinence. BJU Int 2003;92:731-5.

7 Kim TH, Jhoo JH, Park JH, Kim JL, Ryu SH, Moon SW, et al. Korean version of mini mental status examination for dementia screening and its' short form. Psychiatry Investig 2010;7:102-8.

8. Oh SJ, Park HG, Paick SH, Park WH, Choo MS. Translation and linguistic validation of Korean version of the King's Health Questionnaire Instrument. Korean J Urol 2005;46:438-50.

9. Kelleher CJ, Cardozo LD, Khullar V, Salvatore S. A new questionnaire to assess the quality of life of urinary incontinent women. $\mathrm{Br} J$ Obstet Gynaecol 1997;104:1374-9.
10. Zhang L, Zhu L, Xu T, Lang J, Li Z, Gong J, et al. A populationbased survey of the prevalence, potential risk factors, and symptom-specific bother of lower urinary tract symptoms in adult chinese women. Eur Urol 2015;68:97-112.

11. Gavira Iglesias FJ, Caridad y Ocerín JM, Pérez del Molino Martín J, Valderrama Gama E, López Pérez M, Romero López M, et al. Prevalence and psychosocial impact of urinary incontinence in older people of a Spanish rural population. J Gerontol A Biol Sci Med Sci 2000;55:M207-14.

12. Maggi S, Minicuci N, Langlois J, Pavan M, Enzi G, Crepaldi G. Prevalence rate of urinary incontinence in community-dwelling elderly individuals: the Veneto study. J Gerontol A Biol Sci Med Sci 2001;56:M14-8.

13. Tennstedt SL, Link CL, Steers WD, McKinlay JB. Prevalence of and risk factors for urine leakage in a racially and ethnically diverse population of adults: the Boston Area Community Health (BACH) Survey. Am J Epidemiol 2008;167:390-9.

14. Kwong PW, Cumming RG, Chan L, Seibel MJ, Naganathan V, Creasey $\mathrm{H}$, et al. Urinary incontinence and quality of life among older community-dwelling Australian men: the CHAMP study. Age Ageing 2010;39:349-54.

15. Jackson RA, Vittinghoff E, Kanaya AM, Miles TP, Resnick HE, Kritchevsky SB, et al. Urinary incontinence in elderly women: findings from the Health, Aging, and Body Composition Study. Obstet Gynecol 2004;104:301-7.

16. Schreiber Pedersen L, Lose G, Høybye MT, Jürgensen M, Waldmann A, Rudnicki M. et al. Predictors and reasons for help-seeking behavior among women with urinary incontinence. Int Urogynecol J 2018;29:521-30.

17. Hawkins K, Pernarelli J, Ozminkowski RJ, Bai M, Gaston SJ, Hommer $\mathrm{C}$, et al. The prevalence of urinary incontinence and its burden on the quality of life among older adults with medicare supplement insurance. Qual Life Res 2011;20:723-32.

18. Kaşıkçı M, Kulıç D, Avşar G, Şirin M. Prevalence of urinary incontinence in older Turkish women, risk factors, and effect on activities of daily living. Arch Gerontol Geriatr 2015;61:217-23.

19. Teo JS, Briffa NK, Devine A, Dhaliwal SS, Prince RL. Do sleep problems or urinary incontinence predict falls in elderly women? Aust J Physiother 2006;52:19-24.

20. Park J, Hong GR, Yang W. Factors associated with self-reported and medically diagnosed urinary incontinence among community-dwelling older women in Korea. Int Neurourol J 2015;19:99-106.

21. Okamura K, Nojiri Y, Osuga Y. Reliability and validity of the King's Health Questionnaire for lower urinary tract symptoms in both genders. BJU Int 2009;103:1673-8. 
22. Obayashi K, Saeki K, Kurumatani N. Quantitative association between nocturnal voiding frequency and objective sleep quality in the general elderly population: the HEIJO-KYO cohort. Sleep Med 2015;16:577-82.

23. Asplund R. Obesity in elderly people with nocturia: cause or consequence? Can J Urol 2007;14:3424-8.

24. Cameron AP, Lewicky-Gaupp C, Smith AR, Helfand BT, Gore JL, Clemens JQ, et al. Baseline lower urinary tract symptoms in pa- tients enrolled in LURN: a prospective, observational cohort study. J Urol 2018;199:1023-31.

25. Polit DF, Beck CT. Nursing research: generating and assessing evidence for nursing practice. 10th ed. Philadelphia (PA): Wolters Kluwer; 2017.

26. Chiarelli P. Urinary incontinence: the last taboo? Aust J Rural Health 2004;12:277-8. 